\title{
Assessment of Knowledge, Attitudes and Support of Health Professionals towards Biobanks in Eastern Morocco
}

\author{
Saida Lhousni1 ${ }^{1}$ Redouane Boulouiz' ${ }^{1}$ Naima Abda², Mariam Tajir ${ }^{1}$, Mohammed Bellaoui ${ }^{*}$ (D), \\ Meryem Ouarzane ${ }^{1^{*}}$ \\ ${ }^{1}$ Genetics Unit, Faculty of Medicine and Pharmacy of Oujda, University Mohammed Premier, Oujda, Morocco \\ ${ }^{2}$ Laboratory of Epidemiology, Clinical Research and Public Health, Faculty of Medicine and Pharmacy of Oujda, University \\ Mohammed Premier, Oujda, Morocco \\ Email: ‘bmbellaoui@gmail.com, ‘mouarzane@hotmail.com
}

How to cite this paper: Lhousni, S., Boulouiz, R., Abda, N., Tajir, M., Bellaoui, M. and Ouarzane, M. (2019) Assessment of Knowledge, Attitudes and Support of Health Professionals towards Biobanks in Eastern Morocco. Open Journal of Epidemiology, 9, 191-201.

https://doi.org/10.4236/ojepi.2019.93016

Received: May 22, 2019

Accepted: July 27, 2019

Published: July 30, 2019

Copyright $\odot 2019$ by author(s) and Scientific Research Publishing Inc. This work is licensed under the Creative Commons Attribution International License (CC BY 4.0).

http://creativecommons.org/licenses/by/4.0/

(c) (i) Open Access

\begin{abstract}
Background: Health professionals play a key role in increasing the rate of biobanking participation. Here, we assessed the knowledge and attitude of health professionals in Eastern Morocco towards biobanks and their willingness to recruit patients into biobanks. Methods: A cross-sectional study carried out among health professionals working in various public and private health centers in Eastern Morocco. The data were obtained using a self-administered anonymous questionnaire. Results: 600 health professionals were included in the study. Only $37.5 \%$ of them had knowledge of biobanks. Associations analysis showed that among health professionals, physicians had more knowledge of biobanks $(\mathrm{OR}=2.50, \mathrm{p}=0.000)$, and health professionals working at the University Hospital had more knowledge of biobanks compared to those working in the other participating health centers ( $\mathrm{p}<0.001$ ). $82.9 \%$ of the participants were willing to donate their biological samples to biobanks, and $82.8 \%$ supported the recruitment of patients into biobanks. Conclusions: This study indicates that health professionals in Eastern Morocco showed a notable lack of knowledge about biobanks. However, the majority were willing to donate their own biospecimens and supported the recruitment of patients into biobanks. This study was a good opportunity to raise awareness among health professionals about the interest of biobanks in the development of biomedical research in Eastern Morocco.
\end{abstract}

\section{Keywords}

Biobanks, Health Professionals, Knowledge, Attitude, Willingness to Support Biobank, Morocco 


\section{Background}

Biobanks are structures that store human biological samples (tissues, cells, DNA, etc.) and medical and personal information from donors [1]. These structures are associated with a number of ethical, social and legal component. Biobanks empower biomedical research by enabling access of researchers to high-quality biospecimens. Therefore, biobanks are seen as one of the most promising means for personalizing medical care and improving public health [2] [3] [4].

The survival of biobanks depends on continuous supply of samples from donors. Numerous studies demonstrated that the success of biobanks depends on public's attitude and trust in biomedical research [5] [6] [7] [8]. Therefore, it is very important to work on factors that may increase the rate of biobanking participation. As a matter of fact, health professionals play a key role in increasing the rate of biobanking participation [9]. Thus, assessment of the opinion of health professionals about the factors that may affect the willingness of patients to participate in biobanks may provide information on how to approach potential donors and seek their approval.

Currently, biobanks are a relatively new concept in Morocco and no study has been conducted on the knowledge and attitudes of Moroccans, in particular health professionals, towards biobanks. Thus, we assessed in this study the knowledge and attitude of health professionals towards biobanking in Eastern Morocco. We also evaluated their willingness to recruit patients in biobanks. This study was a good opportunity to raise awareness among health professionals about the interest of biobanks in the development of biomedical research in Eastern Morocco.

\section{Methods}

\subsection{Ethics Approval and Consent to Participate}

Our study was carried out according to the ethics guidelines of the Moroccan law concerning the protection of human subjects participating in biomedical research [10]. The authorization to carry out the study was obtained from the Ministry of Health of Morocco as well as from the Head of each participating health center. Before participation in the study, the investigator explained the purpose of the study and informed health professionals that participation in the study was voluntary and that all data will be anonymous and confidential. Verbal consent was obtained before respondents completed the anonymous questionnaires.

\subsection{Study Design and Participants}

This is a cross-sectional study conducted between November 2015 and July 2016 among health professionals working at different public and private health centers in Oujda, which is the main city in Eastern Morocco. This study was carried out in the following health centers: Mohammed VI University Hospital, Al-Farabi 
Regional Hospital, Boussif Diagnostic Center, eight other public health centers and three private clinics. Health professionals enrolled in this study were physicians and paramedical staffs (nurses and lab technicians).

\subsection{Survey Questionnaire}

The survey questionnaire was developed based on several studies [3] [11] [12] [13]. The self-administered anonymous questionnaire was composed of three sections. The first section was about the socio-demographic data of each participant (age, gender, occupation, specialty, etc.). The second section focused on participants' knowledge of biobanks. For participants who have never heard of biobanks, a paragraph explaining the concept of biobanks was included at the end of this second section. The third section was about whether the participants were willing to donate their own biological samples to biobanks, and their willingness to recruit their patients to biobanks (see appendix).

A pilot survey was conducted with a small sample of participants $(n=20)$, to ensure content validity, effectiveness and reliability of the questionnaire. Then, the questionnaires were distributed in the different participating centers by the investigator who explained the purpose of the study and informed health professionals that participation in the study was voluntary and that all data will be anonymous and confidential. Moreover, verbal consent was obtained before respondents completed the anonymous questionnaires. The questionnaires were then collected from participating centers few days later by the investigator.

\subsection{Statistical Analyzes}

All data were coded and analyzed with the SPSS software version 21.0. Descriptive analyses were used to describe the knowledge and attitude of participants toward biobanks according to age, sex and occupation. Univariate logistic regression was carried out to examine the association between socio-demographic factors and other factors related to biobanks such as knowledge, attitude, willingness to donate biospecimens and recruit patient to biobanks. Only variables identified as significant in univariate analyses were included in multivariate analyses. The results have been considered as significant when $p<0.05$.

\section{Results}

\subsection{Demographic Characteristics of the Study Population}

A total of 600 health professionals completed and returned the questionnaire. The socio-demographic characteristics of the surveyed population are shown in Table 1. Among the participants, $60.8 \%$ were female and $39.2 \%$ were male, with a female to male ratio of 1.55 . The mean age was $34.94 \pm 12.27$ years (range 19 65 ) with $42.2 \%$ belong into the class of age 25 - 34 years. Two-thirds of the participants were paramedical staffs $(61.4 \%)$ and $38.6 \%$ were physicians. The majority of participants were from the public sector (94.3\%), while only $5.7 \%$ of participants were from the private sector. 
Table 1. A descriptive analysis of the participants according to the socio-demographic data $(\mathrm{N}=600)$.

\begin{tabular}{|c|c|c|}
\hline & $\mathbf{N}$ & $\%$ \\
\hline \multicolumn{3}{|l|}{ Gender $(\mathrm{N}=592)^{*}$} \\
\hline Female & 360 & 60.8 \\
\hline Male & 232 & 39.2 \\
\hline \multicolumn{3}{|l|}{ Age $(N=576)^{*}$} \\
\hline Mean age \pm SD & $34.94 \pm 12.27$ & \\
\hline Range (years) & $19-65$ & \\
\hline $19-24$ & 108 & 18.8 \\
\hline $25-34$ & 243 & 42.2 \\
\hline $35-44$ & 82 & 14.2 \\
\hline $45-54$ & 70 & 12.1 \\
\hline$\geq 55$ & 73 & 12.7 \\
\hline \multicolumn{3}{|l|}{ Profession $(\mathrm{N}=594)^{*}$} \\
\hline Paramedical staffs & 365 & 61.4 \\
\hline Physician & 229 & 38.6 \\
\hline \multicolumn{3}{|l|}{ Sector $(N=600)$} \\
\hline Public & 566 & 94.3 \\
\hline Private & 34 & 5.7 \\
\hline
\end{tabular}

$\mathrm{N}$ : number of participants; *: number of participants with known information; SD: standard deviation.

\subsection{Knowledge of Biobanks among Health Professionals}

Table 2 shows the analysis of the knowledge of biobanks among health professionals. We found that more than a third of health professionals $(37.5 \%)$ had knowledge of biobanks. Almost two-thirds (62.5\%) of the participants had never heard of biobanks. Among the participants who had knowledge of biobanks, $30.2 \%$ had their information of the concept of biobanks by scientific events, $24.9 \%$ through reading, $18.2 \%$ from Medias, and $5.8 \%$ by combination of several sources (scientific events, reading, media, etc.).

The association analysis of participants' knowledge about biobanks with sociodemographic factors is shown in Table 3. Participants aged between 25 and 34 years had more knowledge of biobanks in comparison with participants belonging to other age groups $(\mathrm{OR}=1.85, \mathrm{p}=0.012)$. The knowledge of biobanks was significantly associated with the profession. Indeed, among the participants, physicians had more knowledge of biobanks $(\mathrm{OR}=2.68, \mathrm{p}=0.000)$. In addition, our data showed that health professionals working at the University Hospital had more knowledge of biobanks compared to those working in the other participating health centers $(\mathrm{p}<0.001)$. Respondent's gender and sector were not significantly associated with biobank knowledge ( $\mathrm{p}>0.05)$. 
Table 2. Knowledge about biobanks among health professionals $(\mathrm{N}=600)$.

\begin{tabular}{ccc}
\hline Neard of biobanks & N & $\%$ \\
Yes & 225 & 37.5 \\
No & 375 & 62.5 \\
Source of information for those who know biobanks & & \\
Scientific event & 68 & 30.2 \\
Reading & 56 & 24.9 \\
Medias & 41 & 18.2 \\
Combination of (scientific event, Reading and medias) & 13 & 5.8 \\
Other & 15 & 6.7 \\
Non responders & 32 & 14.2 \\
\hline
\end{tabular}

$\mathrm{N}$ : number of participants.

Table 3. Association analysis of participants' knowledge about biobanks with sociodemographic factors $(\mathrm{N}=600)$.

\begin{tabular}{|c|c|c|c|c|c|c|c|}
\hline & \multirow[t]{2}{*}{$\begin{array}{l}\text { Knowledge about } \\
\text { biobanks (\%) }\end{array}$} & \multicolumn{3}{|c|}{$\begin{array}{l}\text { Logistic regression } \\
\text { univariate of knowledge }\end{array}$} & \multicolumn{3}{|c|}{$\begin{array}{l}\text { Logistic regression } \\
\text { analysis final model }\end{array}$} \\
\hline & & OR & CI $95 \%$ & $p$-value & AOR & CI $95 \%$ & $p$-value \\
\hline \multicolumn{8}{|l|}{ Gender } \\
\hline Male $^{\mathrm{a}}$ & 41.8 & & 1 & & & & \\
\hline Female & 35.3 & 0.76 & {$[0.54-1.06]$} & 0.110 & & - & \\
\hline Age group & & & & 0.017 & & & \\
\hline $19-24^{\mathrm{a}}$ & 30.6 & & 1 & & & & \\
\hline $25-34$ & 44.9 & 1.85 & {$[1.14-2.99]$} & 0.012 & & & \\
\hline $35-44$ & 39.0 & 1.45 & {$[0.79-2.66]$} & 0.224 & & - & \\
\hline $45-54$ & 31.4 & 1.04 & {$[0.54-1.99]$} & 0.902 & & & \\
\hline$\geq 55$ & 27.4 & 0.85 & {$[0.44-1.65]$} & 0.647 & & & \\
\hline \multicolumn{8}{|l|}{ Profession } \\
\hline Paramedical staffs ${ }^{\mathrm{a}}$ & 28.8 & & 1 & & & 1 & \\
\hline Physician & 52.0 & 2.68 & {$[1.90-3.78]$} & 0,001 & 2.50 & {$[1.75-3.57]$} & 0.001 \\
\hline \multicolumn{8}{|l|}{ Sector } \\
\hline Public $^{\mathrm{a}}$ & 37.9 & & 1 & & & & \\
\hline Private & 30.3 & 0.71 & {$[0.33-1.52]$} & 0.382 & & & \\
\hline Hospital centers & & & & 0.002 & & & 0.018 \\
\hline $\mathrm{UH}^{\mathrm{a}}$ & 44.7 & & 1 & & & 1 & \\
\hline RH & 29.1 & 0.51 & {$[0.33-0.77]$} & 0.001 & 0.61 & {$[0.39-0.93]$} & 0.022 \\
\hline DC & 23.1 & 0.37 & {$[0.15-0.95]$} & 0.038 & 0.40 & {$[0.16-1.05]$} & 0.062 \\
\hline $\mathrm{HC}$ & 28.3 & 0.49 & {$[0.27-0.89]$} & 0.020 & 0.53 & {$[0.29-0.98]$} & 0.044 \\
\hline Private clinics & 30.3 & 0.54 & {$[0.25-1.16]$} & 0.115 & 0.47 & {$[0.21-1.04]$} & 0.063 \\
\hline
\end{tabular}

OR: Odds ratio; AOR: Adjusted Odds Ratio; CI: confidence interval; a: Reference category for each variable, UH: University Hospital; RH: Regional Hospital; DC: Diagnostic Center; HC: health centers. 
When assessing all sociodemographic characteristics in a multiple regression analysis, only variables related to professions and health centers $(A O R=2.50, p$ $<0.001$ and $\mathrm{p}=0.018$ respectively) were significantly associated with the knowledge of biobanks (Table 3).

\subsection{Willingness of Health Professionals to Support Biobanking}

In a question about their willingness to donate their own biospecimens associated to their personal and clinical data to biobanks, the majority of health professionals (82.9\%) showed positive attitudes (Table 4). Most participants (82.8\%), agreed to explain to patients the role of biobanks for the development of biomedical research, and to convince them to participate in biobanks (Table $4)$.

\section{Discussion}

The purpose of this study was to determine the knowledge and the attitude of health professionals toward biobanks as well as their willingness to donate their own biospecimens and to recruit patients into biobanks. This study was also intended to develop awareness on biobanking and to introduce this concept into routine Moroccan hospital practices.

\subsection{State of Knowledge of Biobanks}

Our study demonstrates that biobanks are poorly known among health professionals. This result was expected because the concept of biobank is quite new in Morocco and therefore still poorly known. Many studies carried out in other countries, have also shown that biobanks remained very poorly known among health personnel. For example, an Australian study revealed that the majority of health professionals had no knowledge of biobanks [9]. The lack of knowledge about biobanking was also observed among health students in Saudi Arabia [14]. Regarding the association between the knowledge of biobanks and socio-demographic factors, our study demonstrated that participants aged between 25 and 34 years, physicians, and health professionals working at the University

Table 4. Willingness of healthcare professionals to support biobanking $(\mathrm{N}=600)$.

\begin{tabular}{lcc}
\hline & $\mathrm{N}$ & $\%$ \\
\hline $\begin{array}{l}\text { Would you be willing to provide your biological samples as well as your } \\
\text { personal data to a biobank, knowing that they will be stored in a confidential } \\
\text { manner? }\end{array}$ & 484 & 82.9 \\
Yes & 99 & 17.1 \\
No & \\
Are you willing to explain the role of biobanks in biomedical research to & \\
patients, in order to convince them to participate in biobanks? & 82.8 \\
Yes & 485 \\
No & 101 & 17.2 \\
\hline
\end{tabular}


Hospital had more knowledge of biobanks. Together, our data highlight the necessity to establish awareness about biobanking among health professionals in Eastern Morocco. This can be achieved by implementing an appropriate education and training program on biobanking for health professionals.

\subsection{Willingness of Health Professionals to Donate Biospecimens to Biobanks}

Despite that biobanks are poorly known among health professionals, most participants were willing to donate their own biospecimens associated to their personal and clinical data to biobanks. We found that factors such as gender or age were not significantly associated with the health professionals' willingness to donate biospecimens to biobanks. However, profession was significantly associated with the willingness to donate to biobanks. In fact, physicians were more willing to donate biospecimens to biobanks than paramedical personnel. An Italian study among university students, demonstrated that women were more willing to donate their biological samples to biobanks than men, and medical students or professional nursing were more willing to do so than law students [15]. Another study conducted among senior health students in Saudi Arabia, showed that the majority (89\%) of the participants were willing to donate biospecimens to biobanks for biomedical research purposes [14].

\subsection{Willingness of Health Professionals to Recruit Patients into Biobanks}

Most of health professionals were willing to explain to patients the role of biobanks in biomedical research, in order to convince them to participate in biobanks. This positive attitude was observed in several previous studies [9] [16]. An Australian study has explored the opinion of health professionals on biobanks of cancer, has shown that the majority of participants are very favorable to biobanks [9] [17] [18]. A positive attitude towards the creation of a biobank of DNA has also been observed in a study in the United States and Scotland, where $83 \%$ of health professionals were in favor of creating a DNA biobank [11].

Despite the important finding of this study, there were some limitations. For example, some items of the questionnaire may not be well understood, especially since the majority of health professionals were not aware of biobanks. The other limitation is that the study assessed only a hypothetical willingness to support biobanking, and that an assessement of an actuel participation in a biobank could provide a different, probably lower rate.

\section{Conclusion}

The study provides new information about the knowledge and attitudes of health professionals towards biobanks in Eastern Morocco. Despite limited knowledge of biobanking among health professionals, most participants had a positive attitude towards the setting up of a biobank in Eastern Morocco. This 
finding foresees a bright future for biobanks that would establish in Eastern Morocco.

\section{Acknowledgements}

We are grateful to all health personnel at the participating health centers in Oujda. We also thank the Regional Director of the Ministry of Health in Eastern Morocco for his support. We thank Dr. A. Azzouzi and all the administrative staff of the Faculty of Medicine and Pharmacy of Oujda for their valuable support and encouragement throughout the entire work. We also thank Pr. A. Mazari for proof reading the manuscript.

\section{Conflicts of Interest}

The authors declare no conflicts of interest regarding the publication of this paper.

\section{References}

[1] Hewitt, R. and Watson, P. (2013) Defining Biobank. Biopreservation and Biobanking, 11, 309-315. https://doi.org/10.1089/bio.2013.0042

[2] Barnes, R.O., Parisien, M., Murphy, L.C. and Watson, P.H. (2008) Influence of Evolution in Tumor Biobanking on the Interpretation of Translational Research. Cancer Epidemiology, Biomarkers \& Prevention, 17, 3344-3350. https://doi.org/10.1158/1055-9965.EPI-08-0622

[3] Riegman, P.H., Morente, M.M., Betsou, F., de Blasio, P. and Geary, P. (2008) Biobanking for Better Healthcare. Molecular Oncology, 2, 213-222. https://doi.org/10.1016/j.molonc.2008.07.004

[4] Gaskell, G., Gottweis, H., Starkbaum, J., Gerber, M.M., Broerse, J., Gottweis, U., Hobbs, A., Helen, I., Paschou, M., Snell, K. and Soulier, A. (2013) Publics and Biobanks: Pan-European Diversity and the Challenge of Responsible Innovation. European Journal of Human Genetics, 21, 14-20. https://doi.org/10.1038/ejhg.2012.104

[5] Levitt, M. and Weldon, S. (2005) A Well Placed Trust? Public Perceptions of the Governance of DNA Databases. Critical Public Health, 15, 311-321. https://doi.org/10.1080/09581590500523186

[6] Hansson, M.G. (2009) Ethics and Biobanks. British Journal of Cancer, 100, 8-12. https://doi.org/10.1038/sj.bjc.6604795

[7] Kettis-Lindblad, A., Ring, L., Viberth, E. and Hansson, M.G. (2006) Genetic Research and Donation of Tissue Samples to Biobanks. What Do Potential Sample Donors in the Swedish General Public Think? European Journal of Public Health, 16, 433-440. https://doi.org/10.1093/eurpub/cki198

[8] Johnsson, L., Helgesson, G., Rafnar, T., Halldorsdottir, I., Chia, K.-S., Eriksson, S. and Hansson, M.G. (2010) Hypothetical and Factual Willingness to Participate in Biobank Research. European Journal of Human Genetics, 18, 1261. https://doi.org/10.1038/ejhg.2010.106

[9] Caixeiro, N.J., Byun, H.L., Descallar, J., Levesque, J.V., de Souza, P. and Soon Lee, C. (2016) Health Professionals' Opinions on Supporting a Cancer Biobank: Identification of Barriers to Combat Biobanking Pitfalls. European Journal of Human 
Genetics, 24, 626-632. https://doi.org/10.1038/ejhg.2015.191

[10] (2015) Law No. 28-13 on the Protection of Persons Participating in Biomedical Research. (In French) http://adala.justice.gov.ma/production/html/Fr/190513.htm

[11] Leiman, D.A., Lorenzi, N.M., Wyatt, J.C., Doney, A.S. and Rosenbloom, S.T. (2008) US and Scottish Health Professionals' Attitudes toward DNA Biobanking. Journal of the American Medical Informatics Association, 15, 357-362. https://doi.org/10.1197/jamia.M2571

[12] Meulenkamp, T.M., Gevers, S.J., Bovenberg, J.A. and Smets, E.M. (2012) Researchers' Opinions towards the Communication of Results of Biobank Research: A Survey Study. European Journal of Human Genetics, 20, 258-262. https://doi.org/10.1038/ejhg.2011.216

[13] Whitley, E.A., Kanellopoulou, N. and Kaye, J. (2012) Consent and Research Governance in Biobanks: Evidence from Focus Groups with Medical Researchers. Public Health Genomics, 15, 232-242. https://doi.org/10.1159/000336544

[14] Merdad, L., Aldakhil, L., Gadi, R., Assidi, M., Saddick, S.Y., Abuzenadah, A., Vaught, J., Buhmeida, A. and Al-Qahtani, M.H. (2017) Assessment of Knowledge about Biobanking among Healthcare Students and Their Willingness to Donate Biospecimens. BMC Medical Ethics, 18, 32.

https://doi.org/10.1186/s12910-017-0195-8

[15] Tozzo, P., Fassina, A. and Caenazzo, L. (2017) Young People's Awareness on Biobanking and DNA Profiling: Results of a Questionnaire Administered to Italian University Students. Life Sciences, Society and Policy, 13, 9.

https://doi.org/10.1186/s40504-017-0055-9

[16] Wyld, L., Smith, S., Hawkins, N.J., Long, J. and Ward, R.L. (2014) Introducing Research Initiatives into Healthcare: What Do Doctors Think? Biopreservation and Biobanking, 12, 91-98. https://doi.org/10.1089/bio.2013.0069

[17] André, B., Inger Ringdal, G., Loge, J.H., Rannestad, T., Laerum, H. and Kaasa, S. (2008) Experiences with the Implementation of Computerized Tools in Health Care Units: A Review Article. International Journal of Human-Computer Interaction, 24, 753-775. https://doi.org/10.1080/10447310802205768

[18] Betsou, F., Rimm, D.L., Watson, P.H., Womack, C., Hubel, A., Coleman, R.A., Horn, L., Terry, S.F., Zeps, N. and Clark, B.J. (2010) What Are the Biggest Challenges and Opportunities for Biorepositories in the Next Three to Five Years? Biopreservation and Biobanking, 8, 81-88. https://doi.org/10.1089/bio.2010.8210 


Genetics Unit
$\begin{gathered}\text { Faculty of Medicine and Pharmacy of Oujda, } \\ \text { University Mohammed Premier, } \\ \text { Kingdomof Morocco }\end{gathered}$

Assessment of knowledge, attitudes and support of health professionals towards biobanks in Eastern Morocco

Dear,

As part of our project on the establishment of a biobank at the Faculty of Medicine and Pharmacy of Oujda, we are currently conducting a study on the assessment of knowledge, attitudes and support of health professionals towards biobanks in Eastern Morocco.

The aim of this study is to raise the awareness of healthcare professionals of the crucial role of biobanks in the development of biomedical research, and to evaluate their willingness to recruit patients in biobanks.

We are carrying out this study using an anonymous questionnaire.

We will appreciate your support by completing this anonymous questionnaire. Thank you very much for your great cooperation.

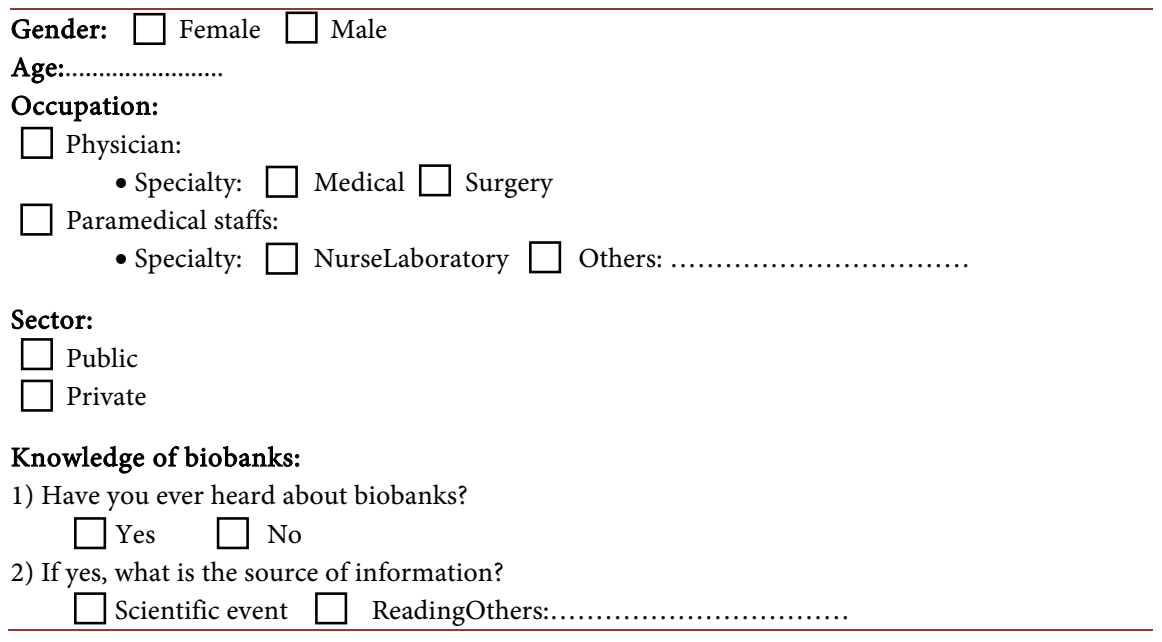

If you have never heard about biobanks, please read the following information about biobanks before completing the questionnaire:

Biobanks are structures that store human biological samples (tissues, cells, DNA, etc.) associated to medical and personal information from donors.

The role of biobanksis to preserve biological samples of good quality and in sufficient quantity to be used at the appropriate time in biomedical research. Biobanks are therefore an instrument for identifying, validating and analyzing genomic, tissue, blood or tumor biomarkers. Biobanks are therefore essential to progress in understanding the mechanisms of disease, to develop diagnostic tools, to predict the effect of treatments and to conduct epidemiological studies.

1) Are you willing to explain the role of biobanks in biomedical research to patients, in order to convince them to participate in biobanks?

$$
\square \text { Yes } \square \text { No }
$$

2) Would you be willing to provide your biological samples as well as your personal data to a biobank, knowing that they will be stored in a confidential manner?

$$
\square \text { Yes } \square \text { No }
$$


Prof. Mohammed BELLAOUI

Head of the Genetics Unit

Faculty of Medicine and Pharmacy of Oujda

University Mohammed Premier, Oujda, Morocco

Thanks 